\title{
Population Health As a Primary Criterion of Sustainability
}

\author{
Anthony J. McMichael \\ National Centre for Epidemiology \& Population Health, Australian National University, Canberra, Australian Capital Territory 0200, Australia
}

\section{INTRODUCTION}

The central, though under-recognized, reason why sustainability is of crucial importance to humanity is because ongoing trends in environmental conditions, at regional and global levels, now jeopardize nature's life-support systems. This has great implications for human well-being and health - and for the rest of the biosphere (McMichael, 2001).

That connection is poorly understood by a generation of policymakers (and researchers!) who have internalized a quasi-Newtonian view of how the world works, and have accepted the neoclassical economic orthodoxy that, via human ingenuity, continuing growth is possible. Currently, therefore, "sustainability" is viewed predominantly in terms of maintaining the assumed upward linear trajectories and moving the global economic engine into ever higher gear. That contrasts sharply with the excellent definition on the Internet's Wikipedia, referring to sustainability as a system of "parallel care and respect for the ecosystem and the people within."

The "EcoHealth" mix of research disciplines therefore has a dual task: (i) doing research that elucidates these relationships, and (ii) communicating the profound nature of that relationship.

Popular culture weighs against ready recognition of this fundamental dependency of health on the natural world. Most people, in day-to-day musings about "health," assume that the main determinants are personal behaviors, consumer choices, local environmental exposures, access to

Published online: July 8, 2006

Correspondence to: Anthony J. McMichael, e-mail: tony.mcmichael@anu.edu.au medical care, and chance. When the natural environment is (apparently) a stable "constant," then that popular assumption about micro-scale determinants may seem tenable. Today, however, it most certainly is not tenable. Population health depends, more fundamentally, on social and economic conditions, water and food supplies, the integrity of ecosystems, biodiversity stocks, microbial ecology, and climate. Those macro-scale determinants of health are now being destabilized, globally, by unprecedented human pressures.

Environmental health research has, for long (and, of course, with many important consequences), studied the effects of localized exposures to specific direct-acting agents (such as heavy metals, pesticides, ionizing radiation, or water-borne microbes). Today, we also face a very different category of environmental health hazard, impinging on human health mostly via systems-based changes to the environment (including climate, food-producing systems, freshwater circulation, and other ecosystem "goods and services").

The recent appearance of these larger-scale, and forward-projecting, systemic risks to population health are a fundamental signal that humankind, at global level, is now on a nonsustainable path. This is a remarkable, new situation-one that our generation must understand, analyze, and respond to. This argument has been foreshadowed by Wilcox and Colwell (2005), with particular reference to infectious diseases:

No issue could be a more fundamental measure of sustainability than public health, and the increasing emergence and reemergence of infectious diseases glob- 
ally is possibly the world's most challenging public health problem today. Yet this problem is incomprehensible without a vastly broadened research perspective, if not an entirely new paradigm-one that is encompassed by biocomplexity and new conceptual frameworks provoking new theories and models.

Nevertheless, in the ongoing sustainability discourse, the population's health is usually regarded as a mere input (a resource for economic productivity)—or else as regrettable collateral damage, the price of "economic development." Besides (goes the conventional reasoning), we can remedy such health problems via specific interventions like health education, food supplements, or vaccines. Meanwhile, a widely espoused model of "sustainability" recognizes that society must achieve balance between environmental, social, and economic priorities (the misleadingly labeled "triple bottom line"). In reality, however, those three priority entities are means; not ends. The ultimate (anthropocentric) reason for seeking sustainability is to underwrite, now and into the future, the quality of human experience. Health and survival are central to that experience.

My basic argument is this:

1. Population health is a systemic manifestation of a population's entire social, cultural, and biophysical environment.

2. The kind and scale of human-induced changes occurring in those three interdependent "subsystems" of the environment-especially the biophysical environment-are historically unprecedented. They therefore pose unusually great, widespread, and long-term risks to health. This risk to population health is at the heart of "nonsustainability."

3. Further, the complexity of Earth's systems and their unpredictability in response to these burgeoning human pressures is currently incompletely understood and, therefore, prudent policy response must accommodate this uncertainty.

4. The scope of environmental health research and risk assessment must be expanded to take these interdependencies and their potential consequences into account.

I next explore several aspects of the relationship between large-scale changes in natural environmental systems and human population health, and identify some of the challenges to researchers.

\section{Human Health Risks from Global EnVironmental Changes (GEC)}

\section{Ecosystems, Biodiversity and Health}

Since 1950, humans have changed ecosystems more rapidly and extensively than in any comparable period in history (Millennium Ecosystem Assessment [MA], 2005). These changes have undoubtedly achieved increases in carrying capacity, primarily via both intensification and extensification of food-producing agro-ecosystems, and thus contributed to gains in human numbers and human health. However, in addition to the widespread damage done to soils, this process has also caused substantial and largely irreversible losses in biodiversity.

These changes in biodiversity have great potential to disrupt ecological systems and affect human societies by reducing nature's services, such as: cleansing of water and air; climate regulation; provision of food, fiber, and other essential materials; pollination; carbon sequestration; and many others. Species extinction and the transport and introduction of alien species into ecosystems, many of them ecologically invasive, vectors or reservoirs for human disease, or both, is occurring on an unprecedented scale.

There has been little research into how these various biodiversity changes affect human health. This resembles the situation in the early 1990s vis-à-vis climate change and health, before that connection began to receive serious research attention. It has taken more than a decade for research in that domain to acquire some shape and momentum.

We know that changes in biodiversity can influence infectious disease risks via many pathways. For example, biodiversity changes may alter the balance between an infectious agent's reservoir hosts (with their variable capacity to then infect humans) and between disease vectors and their predators. The rise of Lyme disease has been well explored in those terms (Ostfeld and Keesing, 2000). The outbreak of Nipah virus disease in central Malaysia in the late 1990s, killing many pigs and over 100 humans, reflected a complex sequence of changes in environmental conditions and ecological relationships. The virus, which naturally infects forest fruit bats, was able to infect commercial pig herds and their attendants following bat migration. This occurred because of declining forest fruit yields, following forest clearance for plantations and pig farming, forest drying because of an intense El Niño event, and, perhaps, effects of intense regional smoke pollution from Indonesia's forest fires. 
These are complex, often systems-based, cause-effect relationships. Their study often requires the piecing together of different facets of the phenomenon, and some expert judgment as to the relative importance of component pathways.

The recent decline of the world's fisheries illustrates how various of these contemporary, large-scale, processes often converge and heighten the damage to life-support systems, before policies can be put in place to prevent possibly irrecoverable changes. The past four decades of increasingly intensive industrial fishing has depleted many great ocean fisheries. Particularly well-known is the rapid collapse of the Grand Banks cod fishery in the late 1980s. Despite the agreed moratorium in 1992, that fishery has not recovered-probably reflecting how an entire ecosystem, after disruption, can undergo a state change via a repositioning of species.

But the plot has thickened. In mid-2005, the UK Royal Society released a report documenting how the increasing concentration of atmospheric carbon dioxide is acidifying the world's oceans (The Royal Society, 2005). This threatens the base of the marine food web since calcification in zooplankton, crustaceans, and shellfish is very sensitive to $\mathrm{pH}$. Concurrently, an article in Science reported a physical shift in various fish populations in the North Sea in association with ocean warming (Perry et al., 2005). Almost two-thirds of fish species had either moved to higher latitudes or to deeper levels.

This combination of three human-induced pressures on the world's oceans threatens the productivity of future fisheries - and hence jeopardizes a very important source of human food (particularly protein), nutrition, and health.

\section{Climate Change and Health}

Humankind is destabilizing the world's climate system and stressing and perturbing climate-sensitive natural systems (IPCC, 2001). This will cause, directly and indirectly, various adverse health risks. Some health gains may occur in some locations, but those will be the exceptions-and may recede as climate change proceeds. The spectrum of health risks includes those from heatwaves, other extreme weather events, changes to air quality, the geography and seasonality of various infectious diseases, effects on local food yields, freshwater supplies, the general vitality of ecosystems and their flow of "services," and the underpinning of livelihoods (McMichael et al., 2006).

The melting of glaciers, sea-ice and permafrost, and various changes in nonhuman biological systems-germi- nating, flowering, nesting, and migration timing-are readily attributable to accompanying temperature changes. Human populations, however, are uniquely insulated by culture and technology, and display great heterogeneity of behaviors and exposures. Hence, attributing impacts to climate change is less easy.

Several recent examples suggest an influence of climate change on patterns of infectious diseases (McMichael et al., 2006). These include the northwards extension of tickborne encephalitis and the tick-vector population in Sweden, associated with warming winters, and the ascent of highland malaria to higher altitudes in parts of eastern and southern Africa. But if malaria ascends within the highlands, is that due to changes in land-use, population movement, reduced mosquito control programs, rising anti-malarial resistance, or regional warming? Not an easy question.

Questions of attribution and quantification of risk appear simpler in relation to extreme weather events. Consider two types: heat waves and hurricanes.

\section{Extreme Weather Events}

As the world warms and regional weather patterns become more variable, there will be more frequent and more intense periods of extreme temperatures. It has been estimated that the probability of occurrence of Europe's extreme heatwave of August 2003 had been approximately doubled by the underlying (mostly human-induced) warming trend over preceding decades (Stott et al., 2004). During that 12-day period, an estimated 30,000-35,000 excess deaths occurred in Western Europe (International Federation of Red Cross and Red Crescent, 2004).

The proportion of heatwave-associated deaths attributable to the contribution of climate change could be plausibly estimated if we knew the probability distributions for the several key parameters, including: the probability that human actions account for an observed underlying warming trend; the probability of occurrence of specified temperature extremes for any given underlying average temperature; and the probability that excess deaths are due to the extra heat per se.

Climate change is likely to cause regional changes in frequency and severity of storms and cyclones. Hurricane Katrina, September 2005, excited debate about whether climate change contributed some influence via the unusually warm surface waters in the Gulf of Mexico. Two recent studies afford plausibility-one reported that the total annual power of tropical cyclones in the equatorial 


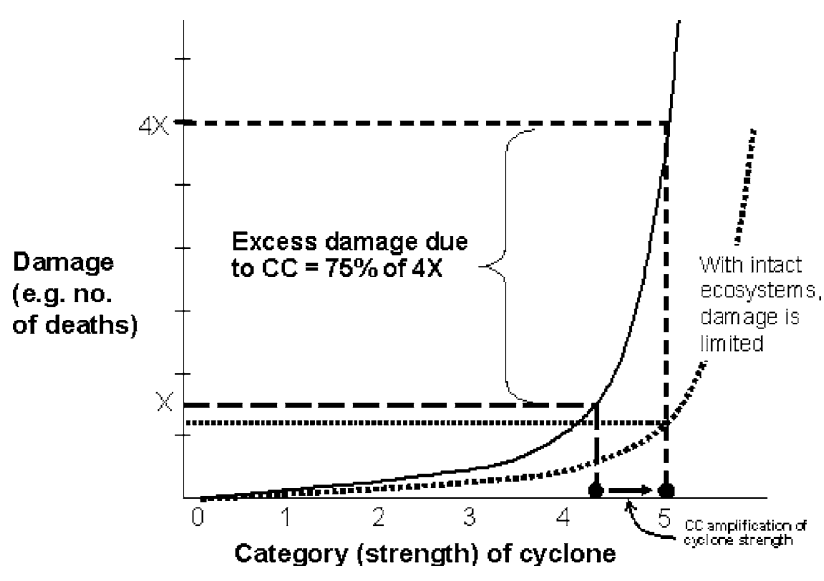

Figure 1. Schematic diagram of damage function between cyclone intensity and number of deaths, and scenarios of attributability. ( $\mathrm{CC}=$ climate change, which amplifies cyclone strength from, say, category $4+$ to category 5. )

northwest Atlantic has been closely correlated with interyear fluctuations and the sinuous time-trend in sea-surface temperature since the 1970s (Emanuel, 2005); the other found, for the same period, no increase in the annual number of cyclones but a doubling in the proportion of category 4-5 cyclones (Webster et al., 2005).

So, can researchers make formal estimates of the portion of the health impact from an event, such as Hurricane Katrina, that is reasonably attributable to climate change? Consider the impact on deaths. Figure 1 shows the hypothetical relationship (damage function) between cyclone intensity and mortality risk. The general shape of this graph is uncontentious (Huang et al., 2001). We can deduce, from published research, that the extra warmth in the Gulf of Mexico would have intensified the cyclone from, say, a category 4 cyclone to a category 5 cyclone. As the former, lesser, cyclone, it would have caused $\mathrm{X}$ deaths, but instead it caused 4X deaths. That is, in this hypothetical example, the climate change component of Hurricane Katrina caused $75 \%$ of the deaths.

We could extend the analysis further. If the coastline, river banks, and wetlands had not been reengineered, impairing their natural protective functions, the damage function might have been as shown, such that, even for a category 5 cyclone, $80 \%$ of the flood damage would have been avoided.

\section{Environmental Refugees}

At the other end of the spectrum of health risks are those resulting from demographic, economic, and social dislo- cations caused by climate change and other GEC. As demographic and environmental (and therefore social and economic) conditions deteriorate in vulnerable regions, immigration and environmental refugee pressures on neighboring (especially richer) countries will increase. This will be accompanied by the many adverse health consequences that typically affect displaced persons-and, perhaps, their host populations. Health impacts may be very large, but will tend to be situation-dependent, multivariate in causation, and difficult to quantify and forecast.

\section{IMPLICATIONS FOR SOCIETY AND POLICY}

The expanding size of the human enterprise is now changing the structures and functioning of the Earth System. This portends a range of large-scale environmental risks to health. Assuming that sustainability is, ultimately, about maintaining Earth's life-supporting capacity, of which human population health is a primary beneficiary, these trends are nonsustainable.

This great predicament poses major challenges to researchers, policymakers, and all of us. The task, now, is to achieve mid-course corrections that will steer the biosphere back to a life-supporting state that will underpin future human well-being and health. The urgency of the task has been stressed by Maurice Strong (2005), an eminent Canadian with long experience in international environmental matters:

I am convinced that the fate of the Earth as a hospitable home for humans will largely be set in the next two or three decades. If we do not move decisively to a transition to a sustainable way of life within this period, prospects will continuously diminish as costs escalate.

\section{REFERENCES}

Emanuel K (2005) Increasing destructiveness of tropical cyclones over the past 30 years. Nature 436:686-688

Huang Z, Rosowsky DV, Sparks PR (2001) Long-term hurricane risk assessment and expected damage to residential structures. Reliability Engineering and System Safety 74:447-459

International Federation of Red Cross and Red Crescent (2004) World Disasters Report. Available: http://www.ifrc.org/publicat/ wdr2004/chapter2.asp

IPCC (2001) Climate change 2001: the scientific basis. Contribution of working group 1 to the third assessment report of the Intergovernmental Panel on Climate Change, Cambridge, UK: Cambridge University Press 
McMichael AJ (2001) Human Frontiers, Environments and Disease: Past Patterns, Future Uncertainties. Cambridge, UK: Cambridge University Press

McMichael AJ, Woodruff R, Hales S (2006) Climate change and human health: present and future risks. The Lancet 367:859869

Millennium Ecosystem Assessment (MA) (2005) Ecosystems and Human Well-Being: Current State and Trends, Vol 1, Hassan R, Scholes R, Ash N (editors), Washington, DC: Island Press, p 2

Ostfeld RS, Keesing F (2000) Biodiversity and disease risk: the case of Lyme disease. Conservation Biology 14:722-728

Perry AL, Low PJ, Ellis JR, Reynolds JD, et al. (2005) Climate change and distribution shifts in marine fishes. Science 308:1912-1915
The Royal Society (2005) Ocean Acidification Due to Increasing Atmospheric Carbon Dioxide. Policy Document 12/05. London: Royal Society

Strong M (2005) Our Environment, Our Health and Our Future: the Next Big Public Policy Challenge. New Thinking Lecture Series, University of Ottawa, 2005. Available: http:// www.newthinkinginitiative.com

Stott PA, Stone DA, Allen MR (2004) Human contribution to the European heatwave of 2003. Nature 432:610-614

Webster PJ, Holland GJ, Curry JA, Chang H-R (2005) Changes in tropical cyclone number, duration, and intensity in a warming environment. Science 309:1844-1846

Wilcox BA, Colwell RR (2005) Emerging and re-emerging infectious diseases: biocomplexity as an interdisciplinary paradigm. EcoHealth 2:244-257 